\title{
NUEVAS CONSIDERACIONES SOBRE LOS TÍTULOS CORTESANOS DEL PINTOR FRANCISCO RIZI
}

Este artículo presenta nuevos detalles sobre la biografía del pintor español Francisco Rizi a partir de una relectura de fuentes ya conocidas; se establece una nueva fecha de su nombramiento como pintor del Rey y se dan nuevas precisiones sobre su nombramiento como pintor de cámara del rey Carlos II de España.

Palabras clave: Rizi; Carlos II; Pintor del Rey; Pintor de cámara.

This article presents new biographical details concerning the Spanish painter Francisco Rizi. Based on a re-reading of already known sources, a new date for the appointment of Rizi as "painter to the King" is established, and his nomination as "painter to the King's chamber" of Carlos II of Spain is clarified.

Key words: Rizi; Carlos II; Painter to the King; Painter to the King's chamber.

Francisco Rizi de Guevara (1614-1685) obtuvo el título de pintor del Rey bajo el reinado de Felipe IV (1621-1665). Durante este periodo, fueron cinco los poseedores de este título: Vicente Carducho, desde 1609, Eugenio Cajés, desde 1612, Velázquez, desde 1622, Angelo Nardi, desde 1631, y Martínez del Mazo, desde 1635. A la muerte de Carducho en 1638, ningún otro pintor

25 Luis Feduchi, Colecciones Reales de España. El Mueble. Madrid, p. 460, lám. 384.

${ }^{26}$ La información precedente sobre Vicente Marzal forma parte de una investigación en curso sobre la escayola intarsiada en España (siglos XVII al XIX). Los documentos sobre Marzal proceden en su mayor parte del Archivo General del Palacio Real de Madrid (AGP Madrid): Expedientes personales, caja 650, exp. 5: Vicente Marzal; caja 436, exp. 9: José Ginés; Reinado de Fernando VII, 402/7; Sección Administrativa General, legajo 5.233 , exp. 13. 
había sido nombrado para este puesto, mientras que había sido costumbre el remplazarlos con cierta rapidez ${ }^{1}$.

Fue su discípulo Rizi quien ocupó su puesto, pero unos dieciocho años más tarde. Este retraso se debió probablemente a las dificultades económicas de aquellos años. Esta situación debe de explicar el que Alonso Cano, que trabajó en importantes encargos para la Corona, no recibiese este nombramiento; o que Zurbarán lo obtuviese tan sólo de modo honorífico tras sus trabajos en la decoración del Buen Retiro, en $1635^{2}$.

Para Rizi el título de pintor del Rey debió de constituir un premio a sus servicios a la Corona, que fueron continuos en esos años; además de su participación en la celebración de la entrada en Madrid de la reina Mariana de Austria en 1649, Rizi había trabajado para representaciones teatrales en la Corte $^{3}$, y en los años siguientes había realizado diversas pinturas para templos del patronato regio. Así, Rizi pintó en 1650 el cuadro de altar para la iglesia de los Capuchinos de El Pardo, de Patronato Regio, y al año siguiente el del Real Convento de Capuchinos de la Paciencia en Madrid ${ }^{4}$; entre 1642 y 1656, debe fecharse el cuadro de altar que pintó probablemente por orden de Felipe IV para la parroquia de Santiago, y que se concibió como un ex voto para agradecer la protección del patrón de España sobre sus reinos ${ }^{5}$. Finalmente, debe señalarse también que el título de pintor del Rey venía a añadirse al de pintor de la Catedral de Toledo, que Rizi había obtenido el 4 de junio de $1653^{6}$.

Como ya había publicado Ceán en 1800, la documentación conservada en el Archivo General de Palacio en Madrid (AGP) señala que Rizi fue nombrado pintor del Rey con gajes el 9 de junio de $1656^{7}$; éstos ascendían a 27.000 maravedíes al año, y a este sueldo vitalicio se añadía el pago por las obras realizadas.

Sin embargo, un documento publicado por Agulló en 1996 nos informa de que el 24 de octubre de 1655, un año antes de lo indicado en el documento del Palacio Real, Rizi otorgaba un poder al maestro mayor de obras de la ciudad de Toledo declarándose "Pintor de Su Majestad y de la Santa Iglesia de Toledo Primada de las Españas" ". Este dato, que aparentemente está en contradicción con el anterior, nos señala que Rizi fue nombrado pintor del Rey antes de lo que suponíamos.

En realidad, Rizi debió de obtener con anterioridad a 1656 el título ad honorem, es decir, de manera nominal, sin derecho a salario alguno, como había ocurrido con otros pintores. De hecho, la obtención del título de pintor del Rey en dos fases no era inusual; fue también el caso de su colega Dionisio Mantuano, nombrado ad Honorem el 8 de julio de 1665 por Felipe IV antes de morir ${ }^{9}$. Sólo el 4 de febrero de 1669, la Reina Madre le concedió los gajes y la pieza del Alcázar que habían correspondido a Angelo Nardi, muerto en 1664, y esto como resultado de una petición

\footnotetext{
${ }^{1}$ Brown, J., La Edad de Oro de la pintura en España, Madrid, 1990, p. 235.

2 Pérez SÁnchez, A. E., Pintura barroca en España. 1600-1750, Madrid, 2000, p. 38.

3 Zapata Fernández de la Hoz, M. T., La entrada en la Corte de María Luisa de Orleáns. Arte y Fiesta en el Madrid de Carlos II, 2000, p. 230 et 244, nota 670.

${ }^{4}$ Pérez SÁnchez, A. E., Carreño, Rizi, Herrera y la pintura madrileña de su tiempo (1650-1700), Madrid, 1986, pp. 64-65.

5 Martín GonzÁlez, J. J., El retablo barroco en España, 1993, p. 94.

${ }^{6}$ CeÁn Bermúdez, J. A., Diccionario histórico de los más ilustres profesores de las Bellas Artes en España, IV, 1800, p. 204.

7 Idem., p. 203.

8 Agulló y Cовo, M., “Antonio y Francisco Rizzi”, Anales del Instituto de Estudios Madrileños, XXXVI, 1996, p. 80 .

9 Archivo General de Palacio (AGP), Caja 2.647, Expediente n. ${ }^{\circ}$ 7, sin foliar. En adelante indicaremos las siglas AGP en las referencias a este archivo.
} 
suya a la Junta de Obras y Bosques ${ }^{10}$. El documento de 1656 que establece la concesión de los gajes a Rizi es también un informe elaborado por la Junta, y no la cédula de su nombramiento, que no figura en el libro del archivo donde encontramos las de sus compañeros.

Que Rizi recibió el título de pintor del Rey en dos tiempos viene confirmado por otros documentos conservados asimismo en el expediente de Rizi del Archivo General de Palacio, y que además nos dan la fecha aproximada del nombramiento (vid. Documentos n. ${ }^{\text {os }} 1$ y 2). Se trata de dos informes realizados en 1661 por la Junta de Obras y Bosques en respuesta a un memorial enviado por Rizi solicitando una habitación en el Alcázar "como la tiene Angelo Nardi su compañero". En ellos se indica que Rizi recibió el título de pintor del rey en razón de sus servicios "seis años ha", es decir, en 1655, y no en 1656. En consecuencia, y como se indicaba en el poder publicado por Agulló, Rizi habría sido pintor del Rey al menos desde 1655, y con toda probabilidad sin gaje alguno ${ }^{11}$.

Pero ésta no es la única cuestión problemática en cuanto a la relación de Rizi con la Corona; a pesar del silencio de Palomino al respecto, a partir de Ceán son varios los historiadores que lo citan como pintor de cámara, sea de Felipe IV, sea de su hijo Carlos, pero este hecho venía interpretándose como una mera imprecisión de términos. Sin embargo, Zapata ha señalado recientemente que Carlos II podría haberlo nombrado pintor de Cámara a principios de 1680, a raíz de su participación en la entrada de María Luisa de Orleáns en Madrid, el 13 de enero de ese año ${ }^{12}$.

Zapata había publicado anteriormente un documento que adjudicaba a Rizi la pareja de retratos ecuestres de Carlos II y María Luisa de Orleáns del Ayuntamiento de Toledo, en que él se presentaba como pintor de cámara de este rey ${ }^{13}$. Este documento es una carta de su propia mano dirigida al Ayuntamiento, a través de la que hacía donación a la ciudad de ambos retratos. La carta fue leída solemnemente en el Cabildo municipal en febrero de 1680, y en ella se presentaba como "pintor de Camara de las Magestades de Filippo IIII y Carlos II"14. Sobre el título de pintor de cámara de Felipe IV no se conoce ninguna otra mención en la documentación, pero del de pintor de cámara de Carlos II existen varias. Recordemos además que la realización de retratos reales era tarea reservada tradicionalmente al pintor de cámara.

En apoyo de la hipótesis de Zapata debe señalarse que Rizi aparece como pintor de cámara de Carlos en la documentación a partir de 1680, cuando parece haberse ganado el favor del joven Rey tras la subida al poder de don Juan José de Austria (1629-1679). Juan José había sido nombrado primer ministro el 23 de enero de 1677, obligando a la Reina Madre a exiliarse a Toledo. Una prueba de este renovado favor real es la concesión de la ayuda de la Furriera en $1677^{15}$. Y además, no debe olvidarse que Don Juan José nombró a Rizi su propio pintor de cámara el 17 de enero de 1678, y que ese mismo año le encargó la decoración de la Capilla del Milagro en las Descalzas Reales, donde realizó su retrato y el del rey.

Por otra parte, el nombramiento de Rizi como pintor de cámara entra en contradicción con el hecho de que éste era un puesto ocupado en principio por un solo pintor, y que Juan Carreño de Miranda (1614-1685) lo detentaba desde 1671, cuando se le nombró para remplazar a Sebastián

10 AGP, Libro de cédulas, Cédula de 1669, folio 328, r-v.

11 Angulo decía haber visto durante la Guerra Civil un cuadro sobre el que Rizzi habría firmado en 1654 como Pintor del Rey. En 1958, sus notas no contenían ni el tema ni el propietario del cuadro, pero sí la firma: "Francus Rizi Pictor Hisp. Regis Anno 1654 Ft". Cf. Diego Angulo, "Francisco Rizi. Su vida, cuadros religiosos anteriores a 1670", Archivo Español de Arte, 1958, p. 103.

12 Zapata Fernández de la Hoz, M. T., op. cit., p. 67, note 133.

13 Zapata Fernández de la Hoz, M. T.; Martínez Gil, F., "Dos retratos reales 'efímeros' de Francisco Rizi en Toledo", Carpetania. Revista del Museo de Santa Cruz, 1987, pp. 171-179.

14 Zapata Fernández de la Hoz, M. T.; Martínez Gil, F., op. cit., p. 176.

15 Pérez SÁnchez, A. E., op. cit., p. 60. 
Herrera Barnuevo (1619-1671). Además, sabemos que Carreño permaneció en el cargo hasta su muerte, ocurrida unos meses antes de la de Rizi, y esto incluso durante el periodo de gobierno de don Juan José de Austria ${ }^{16}$. Pero si recordamos que durante el reinado de Carlos II el número de pintores del Rey se incrementó de manera espectacular, pasando de tres a quince entre 1668 y $1698^{17}$, no parece inverosímil pensar que el rey optase por guardar ambos pintores en esta ocupación.

En cualquier caso, esto es lo que nos confirman dos fuentes posteriores a la muerte de ambos pintores, ocurridas en 1685. Por un lado, se trata del libro de Vera Tassis Historia del origen, invención y milagros de la sagrada imagen de Nuetra Señora de la Almudena, editado en Madrid en 1692, quien cita a Rizi y a Carreño compartiendo el puesto de pintor de cámara ${ }^{18}$. Vera Tassis nos habla del carácter milagroso de la imagen de devoción de la Virgen de la Almudena, de la que cada versión que se realiza es diferente; y esto a pesar de que "son de las mas insignes manos que han ilustrado esta sciencia, pues en ella se desvelaron, casi en nuestros tiempos las de D. Dionisio Mantuano, el Lic. D. Alonso Cano, D Sebastián de Herrera, también Maestro Mayor; y Don Francisco Rizi, Pintor de la Real Cámara de Su Magestad; y sobre todos, D. Iuan Carreño, también Pintor de Cámara...".

La otra fuente son los Principios para estudiar el Nobilísimo y Real Arte de la Pintura de José García Hidalgo, publicados en Madrid en 1693. Aquí se nos informa del modo en que el puesto fue compartido, señalándosenos que Rizi figuraba en la Corte como segundo pintor de cámara ${ }^{19}$. Al tratar sobre su escuela, García Hidalgo nos dice que su antiguo discípulo Isidoro Arredondo, que pasó después a estudiar con Rizi, era en 1696 "segundo Pintor de Cámara de su Majestad", y que había sido nombrado para ocupar "la plaça que tenía el Insigne Don Francisco Rizi".

Por Palomino sabemos que Isidoro Arredondo fue el discípulo predilecto de Rizi al final de su vida. Nos dice también que había sido nombrado pintor del Rey siendo aún joven e inexperto, poco antes de la muerte de su maestro, sin duda por el ascendiente que éste tenía en la Corte. Palomino lo señala burlón y con algo de resquemor con estas palabras: "habiendo reconocido sus padres en él gran inclinación al arte de la Pintura, lo enviaron a Madrid a la escuela de Don José García (hombre de raro, y extravagante humor), y habiendo estado allí algunos meses, lo traspasaron sus padres a la escuela de Don Francisco Rizi; donde aprovechó tanto, que en pocos años (habiéndose empleado con su maestro en algunas obras al servicio de Su Majestad) la primera noticia, que tuvimos que tal pintor había en el mundo, fue haberle hecho merced de su Pintor el señor Carlos Segundo, y con el goce, y gajes desde luego". Probablemente Rizi o su recuerdo ejercieron su influencia para el nuevo nombramiento de segundo pintor de cámara para reemplazarlo.

Pérez Sánchez ya había sugerido que la llegada al poder de don Juan José de Austria habría favorecido la posición de Rizi en la Corte ${ }^{20}$, y en efecto fue quizá este personaje quien estuvo detrás de su nombramiento como segundo pintor de cámara. En cualquier caso, otro documento en que Rizi aparece como tal es un memorial suyo de 1683, dirigido a la Junta que administraba los bienes del entonces difunto don Juan José (1629-1679) ${ }^{21}$. En él Rizi solicitaba el pago de

16 GonzÁlez Asenjo, E., Don Juan José de austria y las artes 1629-1679, 2005, p. 607.

17 Brown, J., op. cit., pp. 288-289. Así, Francisco Leonardoni (1654-1711), nombrado pintor de Cámara de Carlos II en 1693, coincidió en el cargo con Francisco Ruiz de la Iglesia (1649-1704).

18 Citado en Portús, J.; VegA, J., La estampa religiosa en la España del Antiguo Régimen, Madrid, 1998, Apéndice I, doc IX-1-2, p. 531.

19 Citado en Calvo Serraller, F., Teoría de la Pintura del Siglo de Oro, 1991, p. 601.

20 PÉrez SÁnchez, A. E., op. cit., 1986, p. 61.

21 GonzÁlez Asenjo, E., "Francisco Rizi restaurador de pinturas", Archivo Español de Arte, n. 292 , 2000, p. 418. 
al menos una parte de su trabajo de restauración en 1677 de varias pinturas de la colección del ministro; en el texto se presentaba a la Junta como "Ayuda de la Furriera de su Majestad y su pintor de cámara".

En 1678, Rizi se presentaba aún como "pintor de Su Majestad y ayuda de su real furriola [sic] y pintor de Cámara de su alteza", en referencia a don Juan José, por lo que sabemos que en esa fecha aún no poseía el título ${ }^{22}$. Si como sugiere Zapata, Rizi fue nombrado como reconocimiento de Carlos II a los retratos de la entrada real, el nombramiento debió de tener lugar en los primeros meses de 1680 o, como muy temprano, a finales de 1679 .

Lo cierto es que Rizi figura ya como pintor de cámara de Carlos II el 4 de marzo en un documento de la Junta encargada de la organización de la entrada ${ }^{23}$. Esta Junta nombraba a Rizi tasador de las esculturas junto a José de Mora, escultor de Su Majestad, y a Carreño tasador de las pinturas. Carreño y Rizi pudieron haber compartido esta ocupación en tanto que pintores de cámara del rey.

Sea cual sea la fecha del nombramiento, parece cierto que tras el exilio forzado de la Reina Madre en 1677, Carlos II quiso tomar ciertas decisiones de orden simbólico para mostrar una ruptura con su política. Joven y débil de carácter, se situó de buen grado bajo la influencia de su medio-hermano don Juan José, su nuevo valido. Recordemos que fue precisamente la Reina Madre quien nombró a Carreño en 1671, relegando a Rizi a un segundo plano en la Corte. Así, es posible que Carlos II decidiese tomar como pintor de cámara el de su hermano con la intención de distanciarse de su madre. En cualquier caso, bajo su reinado los pintores van a tener una mayor presencia en la Corte, y en el caso de Luca Giordano un claro trato preferencial. Estos favores compensaron quizá en parte el retraso de los pagos e incluso la ausencia de gajes, que se generalizaron aún más.

Nombrar a Rizi como segundo pintor de cámara tenía la ventaja de permitir honrarlo sin necesidad de agraviar a Carreño. Si recibió el título a finales de 1679 o muy a principios de 1680, los importantes encargos cortesanos que sabíamos que Rizi recibió a partir de entonces encuentran ahora mayor sentido. Recordemos que además de los dos retratos reales del Ayuntamiento de Toledo, la Corona le encargó el cuadro del Auto de Fe celebrado en la Plaza Mayor de Madrid el 30 de junio de $1680^{24}$, así como su pendant que celebraba la liberación de Viena de $1683^{25}$, y finalmente, ya hacia el final de su vida, la decoración del nuevo retablo de la sacristía de El Escorial así como su cuadro de altar, que Rizi dejó inacabado a su muerte el 2 de agosto de 1685, y cuyo esbozo no se conserva ${ }^{26}$.

Estas consideraciones ponen de relieve la importancia del papel desempeñado por la figura de Rizi en la Corte de Carlos II, al menos en los últimos años de su vida. Un mejor conocimiento del final de su carrera podría hacer posible que nuevas obras realizadas durante este periodo saliesen a la luz en los próximos años. En 1914, se le atribuía un retrato de Carlos II en la colección del Marqués de Casa Torres ${ }^{27}$, y ya en 1868, Alfred de Courtois le atribuía otro de María Luisa de Orléans, sin fecha ni firma, conservado en el Museo de Pintura de Madrid ${ }^{28}$. Los retratos de To-

22 Barrio Moya, J. L., "El pintor Francisco Rizi y el librero Santiago Martín, tasadores de los cuadros de la biblioteca del Caballero portugués D. Pedro Vallejo (1678) Analecta Calasanctiana, n. ${ }^{\circ}$ 59, 1988, p. 181.

23 ZAPATA FernándeZ DE la Hoz, M. T., op. cit., p. 55.

24 Auto de fe, 1683. Óleo sobre lienzo, $277 \times 438 \mathrm{~cm}$. Madrid, Museo Nacional del Prado (cat. 1126).

25 Angulo Íñiguez, D., "Francisco Rizi. Cuadros de tema profano", Archivo Español de Arte, 1971, pp. 380-381.

26 Pérez Sánchez, A. E., op. cit., 1986, p. 61.

27 LAcoste, Referencias fotográficas de las obras de arte en España, Madrid, 1914, n. ${ }^{\circ} 12$, p. 171.

${ }^{28}$ Courtors lo pone en relación con el pequeño retrato del Auto de fe de 1680 en el Prado, al que según dice inspira o reproduce. Cf. Lettres de Madame de Villars à Madame de Coulanges (1679-1681), edición de Alfred Courtois, Paris, 1868, p. 228. 
ledo y estas informaciones nos confirman que se hace necesario pensar también en Rizi, junto a otros pintores aún no suficientemente estudiados, a la hora de atribuir los numerosos retratos que se conservan sin firmar de Carlos II y su familia para los que hasta no hace mucho tiempo apenas se concebía sugerir otros nombres que los de Juan Carreño de Miranda y de Claudio Coello.

\section{Apéndice documental}

\section{Documento $n .^{\circ} 1$}

"Junta de Obras y Bosques à 27 de agosto de 1661.

Sobre que V[uestra] M[agestad] podra servirse de mandar q[ue] a Fran[cis]co Riçi pintor de V[uestra] $\mathrm{M}$ [agestad] se le de casa de aposento como la tiene Agelo Nardi su compañero, embiando para ello a la Junta de aposento".

"S[e]cr[e]t[ario] Fran[cis]co Manzano".

Nota: "Esta bien".

"Señor.

Fran[cis]co Rizi Pintor de V[uestra] M[agestad] ha referido por Memorial que ha dado en esta Junta que en considerazion de sus servicios le hizo V[uestra] M[agestad] $\mathrm{m}[\mathrm{e}] \mathrm{r}[\mathrm{ce}] \mathrm{d}$ de esta ocupazion seis años ha y se le deuen muchos m[a]r[avedi]s asi de su salario como delas obras que ha hecho, en q[ue] ha puesto el cuidado y asistencia que es notorio, y por que se halla desacomodado y sin casa de aposento como la han gozado todos sus antezesores, y la tienen sus compañeros de mas de los gajes que les tocan, sup[li]ca a $\mathrm{V}$ [uestra] M[agestad] se sirva hazerle $\mathrm{m}[\mathrm{e}] \mathrm{r}[\mathrm{ce}] \mathrm{d}$ de mandar que la Junta de aposento se la de y señale en la forma y como la tiene Angelo Nardi su compañero;

A la Junta Pareze que respeto de ser ciertos los exemplares que fran[cis]co Rici refiere podría V[uestra] $\mathrm{M}$ [agestad] servirse hazerle la $\mathrm{m}[\mathrm{e}] \mathrm{r}[\mathrm{ce}] \mathrm{d}$ que sup[li]ca embiando orden espresa para ello a la de aposento; V[uestra] M[agestad] mandara lo que mas fuere su R[ea]l Voluntad M[adri]d 27 de Ag[os]to de 1661.

"Press[iden]te del conss[ej]o condest[a]bl[e] de cast[ill]a Marq[ués] de eliche, Marq[ués] de fresno". (Archivo General de Palacio, Caja 878, Expediente 37, sin foliar).

\section{Documento $n .^{\circ} 2$}

"Junta de Obras y bosques A 27 de Agosto 1661.

Sobre que V.M. podria servirse de mandar q a françisco Riçi pintor de V.Mgd se le de casa de aposento como la tiene Angelo Nardi su compañero, embiando orden para ello a la Junta de aposento".

"S[ecre]t[ar]io fran[cis]co Manzano".

"Señor,

Françisco Riçi, Pintor de V[uestra] M[a]g[esta]d ha referido por Memorial que ha dado en esta junta, que en consideraçion de sus seruiçios le hizo V[uestra] M[a]g[esta]d $\mathrm{m}[\mathrm{e}] \mathrm{r}[\mathrm{ce}] \mathrm{d}$ de esta ocupaçion seis años ha, y se le deuen muchos $\mathrm{m}[\mathrm{a}] \mathrm{r}[$ avedi]s asi de su salario como de las obras que ha hecho, en que ha puesto el cuidado y asistencçia que es notorio, y por que se halla desacomodado y sin cassa de aposento como la han gozado todos sus anteçesores y la tienen sus compañeros de mas de los gajes q les tocan, suplica a $\mathrm{V}$ [uestra] $\mathrm{M}[\mathrm{a}] \mathrm{g}[\mathrm{esta}] \mathrm{d}$ se sirua haçerle $\mathrm{m}[\mathrm{e}] \mathrm{r}[\mathrm{ce}] \mathrm{d}$ de mandar que la junta de aposento se la de y señale en la forma y como la tiene Angelo Nardi, su compañero;

A la junta Parece que respeto de ser çiertos los exemplares que françisco Riçi refiere. Podria V[uestra] $\mathrm{M}[\mathrm{a}] \mathrm{g}[\mathrm{esta}] \mathrm{d}$ seruirse haçerle la $\mathrm{m}[\mathrm{e}] \mathrm{r}[\mathrm{ce}] \mathrm{d}$ que suplica embiando orden espresa para ello a la de aposento;V[uestra] M[a]g[esta]d mandara lo que mas fuere su R[ea]l voluntad.

M[adri]d 27 de Agosto de 1661".

"Press[iden]te del conss[ej]o Condestable de castt[ill]a, Marq[ué]s de eliche, Marq[ué]s de fresno". (Archivo General de Palacio, Caja 878, Expediente 37, sin foliar). 